\title{
Patrimônio cultural quilombola no Seridó
}

\author{
Sonia Regina Lourenço \\ Professora do Departamento de Antropologia \\ e Programa de Pós-graduação em Antropologia da UFMT
}

CAVIGNAC, Julie \& MACÊDO, Muirakytan K. de (orgs.). 2014. Tronco, ramos e raízes! História e patrimônio cultural do Seridó negro. Brasília/Natal: ABA/Flor do Sal/EDUFRN, $400 \mathrm{pp}$.

O livro é um convite para a reflexão sobre a importância do fazer etnográfico em diálogo com as políticas públicas no âmbito do patrimônio cultural imaterial brasileiro. Esta política reconhece a importância da diversidade étnicocultural e o legado das comunidades negras quilombolas como patrimônio cultural brasileiro. A pesquisa antropológica aliada com a metodologia do INRC (Inventário Nacional de Referências Culturais), proposta pelo Departamento de Patrimônio Imaterial (DPI) do Instituto do Patrimônio Histórico e Artístico Nacional (IPHAN), por meio da promulgação do Decreto 3.551/2000, torna-se da maior importância como política pública que passa a reconhecer as comunidades negras autoidentificadas como "comunidades remanescentes de quilombos”, como sujeitos de direito (O’Dwyer, 2002). As políticas públicas do patrimônio cultural estão coadunadas com o marco legal dos direitos destas populações, como prescreve a Carta Constitucional de 1988 sobre os direitos das co- 
munidades quilombolas por meio do Ato das Disposições Transitórias - ADCT 68, que reconhece os direitos das comunidades negras pelo conceito jurídico de "comunidades remanescentes de quilombos". O que está no centro certo e nas múltiplas vozes que constituem Troncos, ramos e raízes!

Dividido em quatro partes, o livro é o resultado do trabalho de uma equipe transdisciplinar formada por antropólogos, historiadores, linguistas, estudantes de graduação e a participação de pessoas das comunidades quilombolas do Seridó, Rio Grande do Norte. Todos envolvidos no programa Estratégias para uma educação patrimonial em comunidades quilombolas do Seridó- $R N$, iniciado em 2012 e ampliado em 2013, com o novo programa Tronco, ramos e raízes! Inclusão social e patrimônio das comunidades quilombolas do Seridó-RN, abarcando os municípios Caicó, Currais Novos, Acari e Jardim do Seridó. Os programas de extensão universitária foram aprovados pelo edital PROEXT/MEC-SESU, e demonstram quão fértil é a articulação entre o ensino, a pesquisa e a extensão para a produção do conhecimento antropológico.

As pesquisas se dedicaram ao estudo da literatura historiográfica e folclórica sobre a formação sociocultural do estado do Rio Grande do Norte, às transcrições paleográficas, à história oral dos descendentes das comunidades quilombolas e àpesquisa etnográfica. Antes de adentrar no universo histórico e cultural do Seridó, a primeira parte do livro é dedicada à reflexão sobre os conceitos de patrimônio e comunidades quilombolas. O primeiro capítulo, intitulado "Os giros do patrimônio", de Nicolas Adell, professor da Université de Toulouse II, versa sobre a tensão entre a identidade e a dimensão moral do patrimônio inscrita na Convenção de 2003 da Unesco(p.18), particularmente a partir da emergência da categoria do Patrimônio Cultural Imaterial, ao reconhecer a existência de outras formas de expressão intangíveis e/ou simbólicas de universos culturais de povos tradicionais para além da pedra e cal dos monumentos históricos e artísticos nacionais. $\mathrm{O}$ autor conduz o leitor de um "giro espacial" para um "giro moral" propiciada pela noção de patrimônio, e a perspectiva ética nela embutida, na medida em que a "virada pragmática" de que fala está direcionada para as situações, ações, contextos de enunciações, recepção, interpretação, reflexividade e ressignificações de bens culturais de diferentes segmentos, grupos e comunidades (p.27).

O segundo capítulo traz a colaboração de Ellen F. Woortmann (UnB), que reconhece nas comunidades do sertão brasileiro os saberes constituidores da "matriz camponesa" assentada nas relações indissociáveis entre a terra, o trabalho e natureza humanizada (p.55). Em seguida, a reflexão de Carlos Alexandre B. Plínio dos Santos (PPGAS/UnB), fruto de sua tese de doutorado Fiéis Descendentes, recentemente publicada em 2014, analisa as redes de irmandades no período pós-abolição entre as comunidades negras rurais de Mato Grosso do Sul. Santos (p.65-73) apresenta um breve balanço do campo de estudos das ciências sociais desde meados do século XIX, com os primeiros estudos sobre o negro no Brasil, os estudos culturalistas e sociológicos sobre as relações raciais. O autor ressalta que as comunidades negras rurais só irão alcançar o estatuto de "objeto" no campo dos estudos antropológicos a partir dos anos de 1970, com a expansão dos programas de pós-graduação em antropologia social, tornando-se um campo etnográfico por excelência a partir da promulgação da Carta Constitucional e do ADCT 68, e a ampla reivindicação das comunidades quilombolas pelo reconhecimento de seus territórios, interpelando, de um lado, os órgãos governamentais a efetivar direitos, e de outro, os antropólogos para atuar na 
elaboração de relatórios antropológicos como especialistas requisitados para as pesquisas e laudos, atendendo as normativas legais. O levantamento detalhado e abrangente de dissertações, teses e relatórios antropológicos, produzidos desde o início dos PPGAS até o ano de 2010 (p.83-85), revela a imprescindibilidade do trabalho do antropólogo e sua atuação junto a outros órgãos governamentais para a elaboração e consolidação de políticas públicas para as comunidades negras rurais e urbanas quilombolas (p.77).

A segunda parte, A Boa Vista dos negros e a presença afro-brasileira no Seridó, reúne múltiplas vozes de moradores e pesquisadores, marcadas por contornos e linhas às voltas com a memória e a experiência social, enunciando a presença histórica e contemporânea das comunidades negras quilombolas do sertão. Julie Cavignac (p.91-131) focaliza a experiência da pesquisa, da extensão e da produção de relatórios antropológicos resultante do convênio da UFRN com o INCRA, desenvolvidos na comunidade de Boa Vista, no município de Parelhas. Desde 2007, a pesquisa acumulou narrativas, registros fotográficos da paisagem local e da memória dos moradores que reconheceram como principais marcos territoriais edificações, ruínas, cemitérios, e a Festa do Rosário, composta por grupos quilombolas e integrantes da Irmandade do Rosário, considerados os mais significativos da história e do patrimônio cultural afrodescendente (p.125). A diversidade dos dados etnográficos é colocada em contraponto ao discurso da historiografia oficial do Seridó, que relegou a presença da população negra à um regime de invisibilidade, submissão e obediência.

Entrecruzando os artigos, o fragmento do Inventário de Manoel Fernandes da Cruz (1859, p. 135) emerge com uma das primeiras referências de significado histórico das terras da comunidade Boa Vista, cuja regularização fundiária encontra-se em fase de finalização (Cavignac, 95). Em seguida, o depoimento de Gabriela Oliveira, graduanda em turismo e moradora da comunidade, enfatiza o protagonismo das lutas quilombolas por igualdade de direitos e os desdobramentos desta, com a criação do Ponto de Cultura em parceria com a UFRN. Maria Isabel Dantas (175-197) descreve a experiência das oficinas no Ponto de Cultura da Boa Vista e na residência do casal, carinhosamente chamado de Preta e Dodoca, na preparação do chouriço de daminha, receita doce e tradicional feita pelas mulheres que detém o conhecimento especializado da culinária. A preparação do chouriço doce indexa um ritual festivo envolvendo várias famílias na divisão das tarefas entre homens, mulheres e crianças, que por dias e noites mobilizam saberes e a economia de subsistência.

Abre a terceira parte do livro, a análise das relações de trabalho e da economia agrária no sertão da Província do Rio Grande do Norte, de Maria Regina Furtado (UFPR). O estudo abrangente da historiografia local e minucioso dos inventários de 1850 a 1888 (p.236-252) são reveladores da presença incontestável de um grande contingente de africanos e afrodescendentes e, portanto, do sistema escravista no Seridó. A escravidão também é tema do estudo de Helder A. M. de Macedo (254-287) cujo recorte histórico apresenta "dados acerca das histórias de homens e mulheres de cor, provenientes de documentação judicial e religiosa", visando a compreensão do passado da região do Seridó. O estudo do uso dos nomes, da ocupação das terras, apoiado na teoria do parentesco, permitiu a Danycelle Pereira da Silva (PPGAS/UFRS), analisar a memória do exescravo Feliciano José da Rocha, que viveu no Seridó em meados do século XVIII, e de seus descendentes, assim como a transcrição dos inventários de três filhos de Feliciano, que atestam que este ex-escravo possuía propriedades de 
terras adquiridas por meio de negociações e alianças de casamento (p.307). A autora pretende não só identificar os "rastros" da escravidão, mas apontar que no contexto do sistema escravista, determinados sujeitos ocuparam posições e construíram relações sociais não apenas pelo regime senhor versus escravo, o que não significa afirmar que estas mesmas relações devam ser generalizadas para todo o regime de escravidão do sertão do Seridó, como atestam os capítulos anteriores do livro. No final da terceira parte, Dona Zélia Tum, moradora da comunidade, faz referências aos povos da África (Angola, Moçambique e Congo), identificados como seus antepassados, ao sistema escravista e aos quilombos de Palmares. A perspectiva de Dona Zélia sobre a história da escravidão articula-se com as memórias de seus ancestrais dedicados ao trabalho nas roças, e conclui sua narrativa colocando-se como protagonista de sua história, consciente de seus direitos de cidadã quilombola.

A quarta parte do livro é dedicada inteiramente ao estudo antropológico e histórico das Irmandades Negras do Seridó. À luz da perspectiva histórica, Muirakytan K. de Macêdo (UFRN) analisa a formação das Irmandades de Nossa Senhora do Rosário no Seridó, que remonta ao "coroamento festivo datada em 1773 na Vila do Príncipe (hoje Caicó)" das realezas negras (p.329), feita e permeada de tensão entre as irmandades e o clero. No Seridó, estão registradas em documentos históricos de arquivos e na memória de músicos e dançarinos, integrantes destes coletivos negros (p. 331-336). No contexto atual, identifica quatro reinados que compõem a irmandade do Rosário de Caicó: "Samanaú, São João do Sabugi, Rio do Peixe e Riacho de Fora” (p.337). Estas Irmandades guardam semelhanças entre si que remontam às confrarias coloniais, a "corte composta por reis, juízes e súditos" (p.340), conduzida para a igreja "pelos lanceiros, bandeiras, tambores e pífaros" que dançam e cantam músicas instrumentais em performances músico-coreográficas realizadas em datas comemorativas diversas por cada comunidade. São, como enfatiza o autor, "monumentos" da memória afro-brasileira no sertão. Diego Marinho de Gois (UFOPA) dedica-se ao estudo das narrativas de integrantes da Irmandade de Nossa Senhora do Rosário de Jardim do Seridó, que ao mesmo tempo relembram as memórias das festas e atualizam a continuidade de suas práticas. Bruno Goulart (PPGAS/UnB) faz uma crítica às abordagens dos estudos de folclore que classificavam as congadas ou festas das Irmandades como sobrevivências do passado, ora de origem apenas lusitana, como fez Câmara Cascudo, ora como "reminiscências e produtos do arcaísmo", como escreveu Veríssimo de Melo. Goulart convida-nos a interpretar as festas dos "negros do Rosário" em seu potencial político e de afirmação étnica (p.376). Fechando o livro, os artigos de Fábio de Melo Morais, graduado em Ciências Sociais, e o estudo de Lourival Andrade Júnior (URFN) e de Mônica Luiza Belotto de Oliveira Andrade (URFN) mostram como as festas das Irmandades de Nossa Senhora do Rosário dos Negros na região do Seridó atualizam memórias, identidades, operando cenários músico-coreográficos e redes de reciprocidade que criam e recriam laços de sociabilidades.

Todas as perspectivas esboçadas no livro são um convite ao leitor para a compreensão dos modos de saber e fazer do patrimônio cultural imaterial, considerado em seus processos de transmissão, recriação e ressemantização. Estes saberes são constituídos por um mundo relacional no qual encontram-se pessoas, santos, seres mito-cosmológicos, narrativas, memórias, música e dança, que apontam para o mundo da diferença do pertencimento étnico. Os bens, as formas expressivas, os artefatos, selecionados e significados, estão correlacionados 
às outras propriedades de ordem mágica, religiosa, econômica e estética, inscritos nas práticas sociais de comunidades como as do Seridó. A garantia para a continuidade física e cultural de grupos étnicos como as comunidades negras quilombolas está coadunada com os troncos, as raízes e os ramos que constituem seus contextos de vida. Nestes, há um patrimônio cultural pulsante em suas formas expressivas, na culinária, na religiosidade, na organização social, nas formas de produção comunitária e na memória coletiva alicerçadas em redes recíprocas de trocas de bens, palavras e pessoas. Tronco, ramos e raízes! é uma obra coletiva cujas metáforas fazem justiça ao mundo dos sentidos no Sertão do Seridó.

\section{Referências}

ARRUTI, José Maurício A.P. Mocambo: Antropologia e história do processo de formação quilombola. Bauru- São Paulo Edusc, 2006.

O'DWYER, Eliana Cantarino. (Org). Quilombos: identidade étnica e territorialidade. Rio de Janeiro. Editora FGV, 2002 p.83-108. 